\title{
Una propuesta organizativa para la materia "redes de computadoras" en un ambiente semipresencial
}

\section{Propuesta para trabajo en redes}

Ing. Marcos Zambrano Zambrano.Mg. $\left(^{1}\right)$

Ing. Manuel José Linares Alvaro M.Sc. $\left({ }^{2}\right)$

Ing. Martha Lorena Mendoza Navarrete Mg.. $\left({ }^{3}\right)$

( $\left.{ }^{1}\right)$ Universidad Laica Eloy Alfaro de Manabí, Ecuador

(2) Universidad de Granma, Cuba

(3) Universidad Laica Eloy Alfaro de Manabí, Ecuador

Contacto: marcoszambrano@hotmail.com

Receptado: 02/10/2015 Aceptado: 14/11/2015

\section{Resumen}

En la Universidad Cubana, ha quedado establecido en varias carreras universitarias, como la de Ingeniera en informática, la aplicación del plan de estudios D, caracterizado por emplear una modalidad semipresencial, y poseer una marcada disposición a la educación constructivista y significativa. Esta carrera posee en su plan de estudios asignaturas, como "Redes de Computadoras", que requieren de laboratorios correctamente equipados que no siempre están disponibles debido a los altos costos y por consiguiente, a lo escasos que resultan los diferentes dispositivos que se emplean en las redes informáticas. En un ambiente que utilice cualquiera de las modalidades educativas antes mencionadas, esta situación se hace aún más crítica .El presente trabajo, se enmarca en la necesidad de dar soluciones a la problemática anterior. La idea central es organizar los contenidos de la asignatura Redes de Computadoras, usando mapas conceptuales a los cuales estén asociados recursos multimedios tales como textos, imágenes, animaciones, y sobre todo, simulaciones de procesos o equipos propios de las redes de computadoras, y luego compartirlos en una red informática, de manera que permitan, en primera instancia, resolver las 
Rev. SINAPSIS, Vol. 7, N², Diciembre 2015

carencias señaladas y en general constituyan un soporte de apoyo a la enseñanza de la materia.

Palabras claves: Redes de computadoras, mapa conceptual, enseñanza a distancia, routers, protocolo IP

\title{
An organizational proposal for the subject "computer networks" in a blended learning environment
}

\begin{abstract}
In the Cuban University it has been established in several university courses, such as computer engineer, application of curriculum D, characterized by employing a blended format, and have a strong disposition to constructive and meaningful education. This race has in its plan of subjects studies, such as "Computer Networks", which require properly equipped laboratories are not always available due to high costs and therefore to the few that are different devices used in the computer networks. In an environment that uses any of the educational methods above, this situation more critical .The present work is still done, is part of the need to provide solutions to the above problems. The central idea is to organize the contents of the course Computer Networks, using conceptual maps which associated multimedia resources such as text, images, animations, and above all, process simulations or own teams of computer networks are, then share on a computer network, so as to allow, in the first instance, to resolve the identified gaps and generally constitute a support to support the teaching of the subject.
\end{abstract}

Keywords: Computer networks, conceptual map, distance learning, routers, IP protocol

\section{Introducción}

La Universidad Cubana ha modificado sustancialmente las modalidades y planes de estudio. El proceso docente que se desarrolla actualmente en las instituciones universitarias cubanas, sustentado generalmente por el plan de estudios " $D$ ", se caracteriza por ser semipresencial, marcadamente constructivista y significativo; propiedades que han jugado un papel determinante en este proceso de renovación, pues se ha facilitado el acceso a la Educación Superior a un considerable número de jóvenes. Las carreras de perfil informático de la 
Rev. SINAPSIS, Vol. 7, Nº 2, Diciembre 2015

ISSN 1390 - 9770

Universidad de Granma, no son una excepción, lo que implica un gradual reordenamiento de los modelos y estrategias pedagógicas, así como el empleo novedosos materiales y herramientas educativas.

En estas modificaciones que se están introduciendo en el sistema de la educación superior cubano, los sistemas informáticos, tales como las computadoras, las redes, los sistemas de manejo de contenidos y los programas educativos, juegan un papel determinante.

Autores como Venegas y Chrobak (2004), plantean que en los últimos años la expansión de la técnica ha crecido exponencialmente, destacando solamente algunas de estas especialidades, cuyo crecimiento en los últimos años ha sido explosivo; la Electrónica, la Computación, y las Telecomunicaciones, disciplinas recientes con una gran aplicación que han contribuido a la modificación del entorno, y este fenómeno, ha afectado todas las esferas de la vida, incluyendo la de la educación. (Benegas and Chrobak 2004)

Estos autores sostienen que las implicaciones del uso las actuales tecnologías de la información y las comunicaciones en la educación, han sido muy amplias, ya que educar es precisamente una forma especial de comunicación. Las posibilidades de consulta del estudiante que tiene acceso a la red, por solo mencionar algun ejemplo, se potencian de manera casi ilimitada y sus tiempos de búsqueda pueden reducirse considerablemente.

A través de las redes, la ciencia llega a todos, de forma que en el presente no se trata solo de conservar la información, sino de producirla y organizarla, no para retenerla sino para diseminarla a un sinnúmero de usuarios con características y necesidades de información diferentes. (Sánchez 2003)

Uno de los retos básicos de la educación actual es preparar a las personas para ser capaces de participar plenamente en una sociedad plagada de información en la que el conocimiento es fuente crítica de desarrollo social y económico. (Cornella 1999), En dicha sociedad la colaboración productiva es pieza clave del conjunto de redes de organizaciones interactivas abiertas al cambio incesante, por ello, la educación actual requiere la transformación de los mecanismos de transmisión del conocimiento, y las aplicaciones educativas programadas en 
Rev. SINAPSIS, Vol. 7, No 2, Diciembre 2015

ISSN 1390 - 9770

computadoras son algunas de las herramientas que están posibilitando modificar este proceso. (Brunner 2002)

La Psicología educativa ha generado estrategias de aprendizaje para que los estudiantes se vuelvan aprendices estratégicos y con ello mejoren, conscientemente, sus prerrequisitos de estudio, un ejemplo claro de estos procedimientos se denomina "Mapa Conceptual", en el cual el estudiante debe identificar los conceptos básicos, relacionarlos y generar proposiciones. (Ausubel, Novak et al. 1989)

Los Mapas conceptuales constituyen una de las herramientas más utilizadas en la gestión del aprendizaje por la posibilidad que estos ofrecen de personalizar el aprendizaje, compartir conocimiento, y para aprender a aprender. Al mismo tiempo se desarrollan a gran velocidad múltiples iniciativas o estándares que permiten compatibilizar los contenidos desarrollados en diferentes plataformas y entornos educativos. (Iriarte, Duch et al. 2002)

Ausubel, et al, en 1978, formularon la teoría del aprendizaje significativo, que ha resultado ser un gran aporte para el perfeccionamiento de la educación. Un aprendizaje se dice significativo cuando una nueva información (concepto, idea, proposición) adquiere significados para el aprendiz a través de una especie de anclaje en aspectos relevantes de la estructura cognitiva preexistente del individuo.

Basándose en aprendizaje como procesamiento de información y más específicamente en la línea de Ausubel del aprendizaje significativo, es que Novak introduce los mapas conceptuales como una respuesta al aprendizaje significativo, dentro del marco de un programa denominado “Aprender a Aprender". (Ausubel, Novak et al. 1978)

Se trata de una propuesta metodológica de carácter abierto y por tanto, lo importante es la revisión crítica y la adaptación a las necesidades curriculares de cada profesor. Como ya se sabe, no todas las experiencias didácticas tienen los mismos resultados en los distintos grupos y niveles. 
Rev. SINAPSIS, Vol. 7, Nº 2, Diciembre 2015

Las carreras que se estudian en la Universidad de Granma, y más específicamente, la carrera Ingeniería en Informática, no constituyen una excepción de toda esta revolución que está experimentando la educación moderna. Este trabajo se ha realizado a apartir de un problema detectado en la asignatura "Redes de Computadoras", y basándose lo anteriormente mencionado.

\section{Fundamentación y resultados.}

\subsection{Situación problémica}

La enseñanza de algunas asignaturas en general y de la materia "Redes de Computadoras" en particular, específicamente en carreras de perfil Informático como la Ingeniería Informática, se enfrenta a algunos problemas, relacionados con sus propias características:

- Las actividades docentes durante la enseñanza de la asignatura antes mencionada, y sobre todo, las prácticas, exigen de laboratorios correctamente equipados y modernas instalaciones que se vuelven obsoletas rápidamente, lo cual implica el uso de una apreciable cantidad de recursos financieros y materiales, que no están siempre disponibles en los centros de enseñanza, por ejemplo, no siempre se cuenta con un router avanzado, un switch de capa III, o simplemente, una red informática actualizada con los estándares modernos para que estudiantes y profesores realicen sus prácticas y actividades docentes.

- La asignatura trata gran cantidad de contenidos que en no pocas ocasiones resultan ser abstractos, difíciles de demostrar en la práctica, los cuales frecuentemente, son complejos y presentan dificultades para ser adecuadamente comprendidos por parte de los alumnos.

- La asignatura posee gran cantidad de contenidos teóricos, lo cual implica un mayor esfuerzo por parte de sus estudiantes durante su autopreparación.

- A lo anteriormente mencionado, es preciso añadir que, el proceso docente actual se caracteriza por tener un marcado carácter semipresencial y en no pocos casos, a distancia, con marcadas tendencias constructivistas, donde la virtualización posee un destacado papel. 


\section{Rev. SINAPSIS, Vol. 7, Nº 2, Diciembre 2015}

Los hechos anteriores dificultan el alcance de ciertas habilidades y disminuyen la calidad de la docencia, pues, no siempre existen los laboratorios y condiciones requeridas para el normal cumplimiento de los objetivos de la asignatura y casi nunca se cuenta con el equipamiento necesario para ser empleado con fines docentes. Para tratar de suplir esas carencias, se realizaron las siguientes preguntas científicas:

¿Se puede crear una herramienta que aprovechando las tecnologías de la información y las comunicaciones contribuya a elevar la calidad del proceso docente y por consiguiente, el aprendizaje de los estudiantes, en la asignatura "Redes de Computadoras de la carrera "Ingeniería Informática", basada en una modalidad educativa semipresencial y constructivista?

¿Se puede organizar o representar el conocimiento o los contenidos de alguna forma general que permita un fácil acceso a recursos virtuales que ayuden a suplir las carencias señaladas?

\subsubsection{Problema.}

A partir de la situación descrita, se determinó que el problema existente consistió en la limitación o insuficiencia en la adquisición de habilidades por parte de los estudiantes en la asignatura Redes de Computadoras, de la carrera de Ingeniería Informática en la Universidad de Granma, ocasionada principalmente, por la falta de actividades prácticas debido a la escasez de equipos y dispositivos de redes, así como disponibilidad bibliográfica, trazándose a partir de aquí, como objetivos de esta investigación los siguientes:

- Presentar una propuesta organizativa para la asignatura Redes de Computadoras, que facilite el acceso a sus contenidos y brinde recursos virtuales de apoyo al aprendizaje en entornos educativos a distancia, mediante la organización de sus contenidos basado en forma de un mapa conceptual multimedios.

- Probar un sistema cliente - servidor que permita trabajar con mapas conceptuales y al que se pueda acceder desde cualquier computadora conectada a la red Universitaria Nacional (RedUniv). 
Rev. SINAPSIS, Vol. 7, N², Diciembre 2015

ISSN 1390 - 9770

\subsection{Metodología.}

La investigación contó con varias etapas, la primera consistió en el diagnóstico y confirmación del problema científico, para ello se realizaron entrevistas a profesores de experiencia en la asignatura, así como encuestas a estudiantes que se encontraban cursando la misma. También fueron entrevistados estudiantes de la carrera que ya habían aprobado la asignatura. En esta fase también se comenzó con la elaboración del estado del arte.

1.2.1 Elaboración de los recursos multimedios para el mapa conceptual.

Teniendo en cuenta los programas y planes de estudio de la materia, se lograron reunir más de 300 recursos multimedios, como videos, animaciones, simulaciones, imágenes de procesos propios de las redes, aplicaciones (principalmente simuladores), y ejercicios asociados a éstas. La mayor parte de los recursos, fueron elaborados por parte del colectivo de profesores de la asignatura, otros, se descargaron de redes públicas, teniendo en cuenta siempre su licencia de empleo. Posteriormente se diseñó el mapa conceptual y, se eligió e instaló el software a utilizar y finalmente se creó, con ayuda de éste, el mapa conceptual al cual se le integraron los recursos virtuales.

\subsubsection{Diseño del mapa conceptual.}

Por las características del conocimiento que se deseaba representar, requería de un mapa que facilitara que, partiendo de un concepto primario (Redes de Computadora), se pudieran derivar a otros de menor jerarquía (criterios de clasificación de las redes y organización estructural de éstas, etc); y a su vez de estos, se obtuvieran otros (tipos de redes por su topología, tamaño, etc), es por ello que fue elegido un mapa conceptual jerarquizado, en el que los conceptos más generales se encontraban en la parte superior del mapa, y los de menor jerarquía, en los niveles inferiores.

Al igual que la lógica del Proceso Docente Educativo, la estructura del mapa conceptual propuesto, fue diseñada, partiendo de las Redes informáticas como un concepto integrador, del cual se deriva todo un conjunto de aspectos y conceptos secundarios. En todo momento se trató (y en la mayoría de los casos, se consiguió), de seguir la lógica y la estructura de la asignatura de acuerdo a la distribución de temas y unidades. 


\section{Rev. SINAPSIS, Vol. 7, N² 2, Diciembre 2015}

Por lo extenso que resultan los contenidos, se decidió seccionar el mapa, de manera que el conjunto de mapas resultantes, fueran lo más sencillos y comprensivos posible, para ello, se creó, un mapa inicial en el que se tratan los aspectos mas generales relacionados con las redes informáticas, el cual se corresponde con los primeros contenidos del primer tema de la asignatura. (Figura 1).

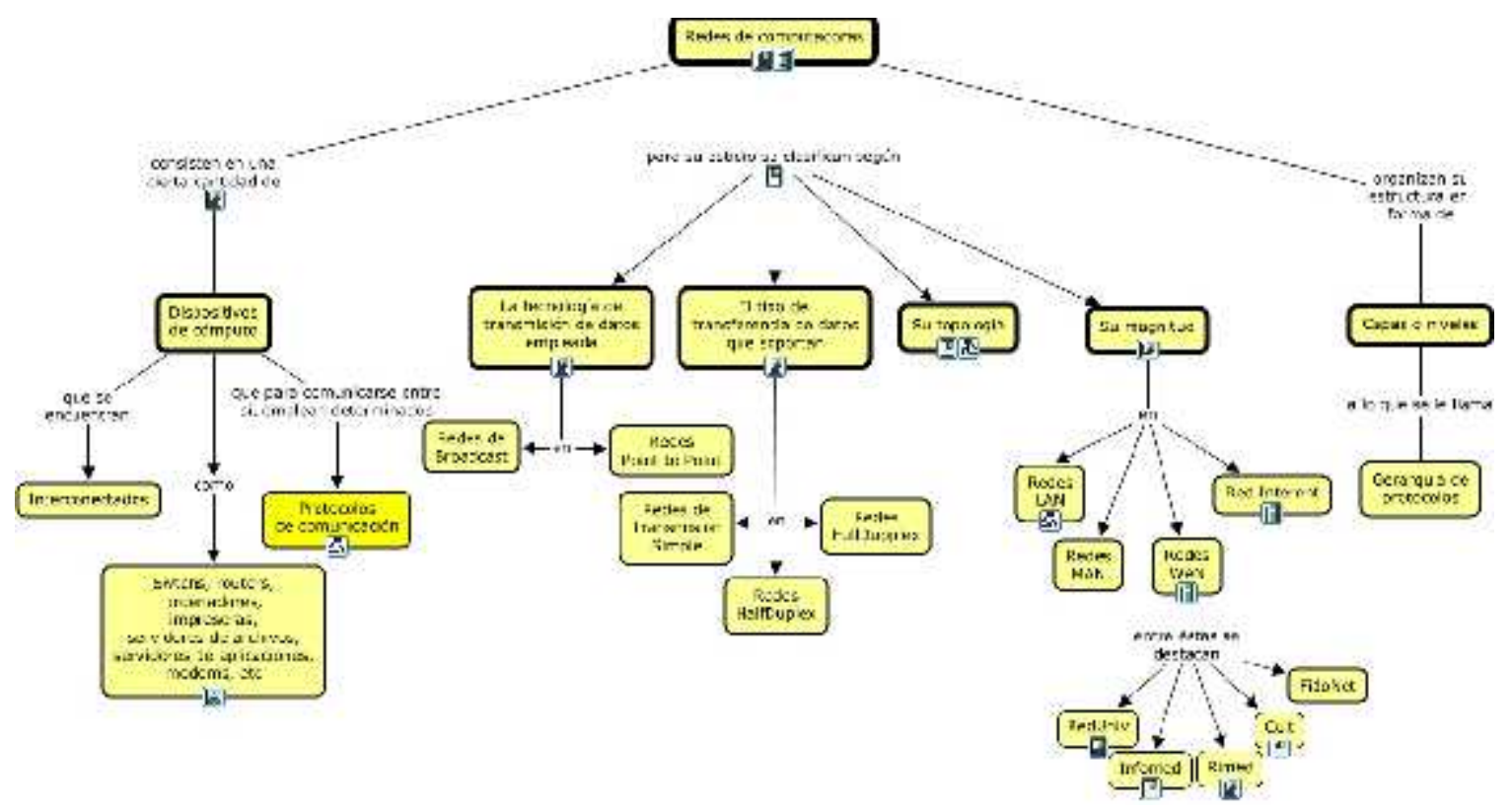

Figura 1. Mapa inicial de la asignatura "Redes de Computadoras".

De los nodos del mapa conceptual inicial, parten otros mapas con conceptos más específicos: los dedicados a los protocolos de comunicación y transmisión de datos, el destinado a la clasificación de las redes de acuerdo a su topología y el que caracteriza a las redes LAN. En la figura 1, puede notarse también que el nodo "Protocolos de comunicación" presenta un color más brillante que el de los otros que contienen ramificaciones a otros mapas conceptuales, esto se hizo para dar una idea al estudiante, de que este nodo es el que los conducirá a otros temas de la materia, o lo que es lo mismo, es el que mantiene el hilo conductor de la secuencialidad lógica del proceso docente.

En la figura 2, se detalla, el mapa conceptual que representa los contenidos relacionados con los protocolos de comunicación en las redes de ordenadores. Al igual que en el mapa anterior, se parte de la representación del concepto de protocolos, su clasificación, y dentro de ésta, cuales son los protocolos actuales comprendidos dentro de cada clase, en este mapa también se abordan los contenidos de los protocolos y las redes estructuradas en capas. Desde estos 


\section{Rev. SINAPSIS, Vol. 7, N² 2, Diciembre 2015}

mapas, existen enlaces a otros que tienen como propósito brindar información más detallada y profunda de cada uno de las protocolos existentes. Note el nodo "TCP/IP" señalado como el que conduce al mapa del siguiente tema de la asignatura (Tema II. El protocolo IP).

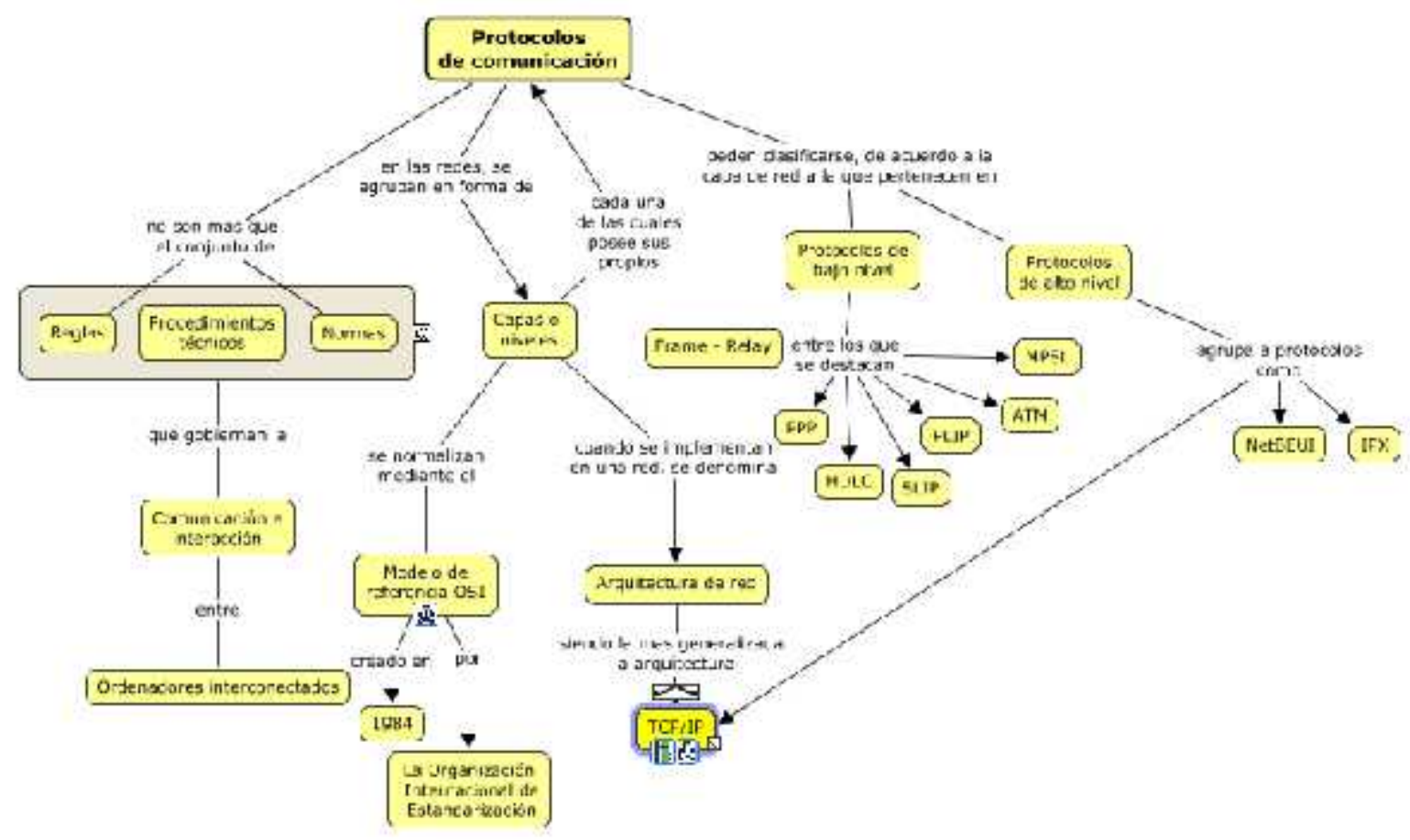

Fig. 2: Mapa conceptual donde se representan los conceptos y las relaciones básicas de los protocolos de comunicación.

Siguiendo estos criterios, se crearon los mapas del resto de los temas de la asignatura. Por lo abstracto de los contenidos, se trató de explotar al máximo el empleo de imágenes, videos, simulaciones y animaciones que ilustren los procesos propios de las redes informáticas (Figura 3).

Es importante comentar que en estos momentos, tanto el mapa conceptual, como la elaboración de los recursos multimedios, se hallan en fase de elaboración y desarrollo, por ello, en muchos nodos o conceptos, aún no existe gran cantidad de recursos multimedios asociados a ellos, pero se espera, que una vez concluido toda el proceso, cada nodo cuente con una abundante y variada cantidad de recursos multimedios.

En el sistema se profundizó bastante en los contenidos del segundo tema, el dedicado a la versión 4 del protocolo IP, pues aquí se tratan los aspectos teóricos y prácticos del protocolo más empleado a nivel mundial, no solo en la red global o la llamada Internet, sino también en intranets, redes privadas, de tipo LAN, MAN y WAN, incluso, se abordan aspectos que no están contenidos de forma explícita en los objetivos de la asignatura, como la caracterización 


\section{Rev. SINAPSIS, Vol. 7, Nº 2, Diciembre 2015}

de los protocolos de bajo nivel, los principales datos biográficos de sus creadores, detalles de versiones anteriores a la actual, etc; pues siempre se valoró la posibilidad de que ciertos estudiantes motivados, desearan profundizar en el estudio de estas materias, y desde luego, se tuvo en cuenta la eventualidad de que este material pudiera ser de

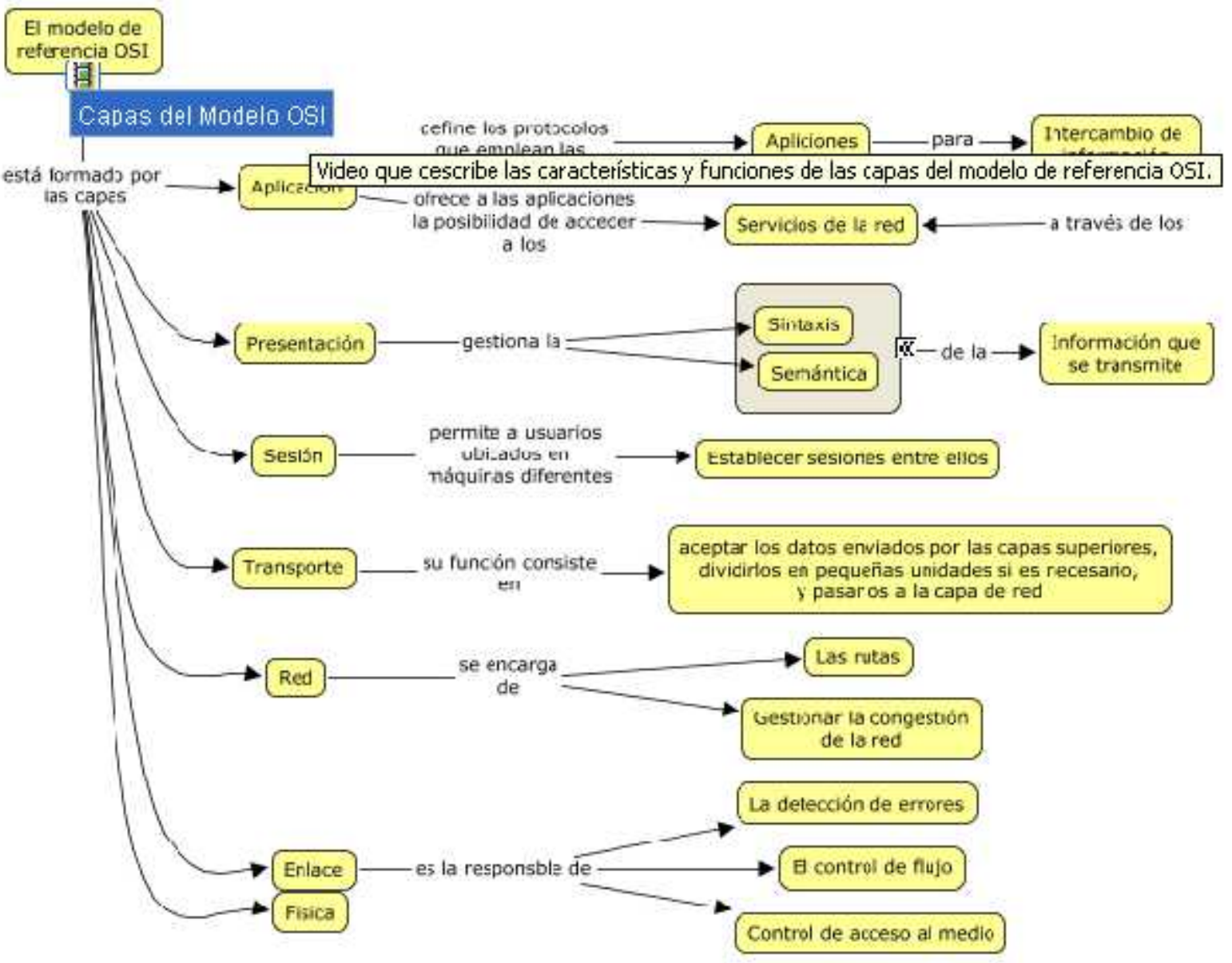

Figura 3. Mapa conceptual dedicado al modelo de referencia OSI, mostrando un video donde se explican las funciones de cada una de sus capas.

interes por parte de profesores y estudiantes de otras carreras más íntimamente relacionadas con las telecomunicaciones.

Por otra parte, este tema es el que históricamente ha presentado mayores dificultades en su comprensión y asimilación por parte de los estudiantes.

En el mapa se incluyeron el simulador de redes, encaminadores y dispositivos de red "GNS3”, y el simulador de máquinas virtuales (QUEMU), mediante los cuales y con la 


\section{Rev. SINAPSIS, Vol. 7, No 2, Diciembre 2015}

ayuda del profesor, los estudiantes los podrán instalar en sus computadoras, o emplearlos en los laboratorios de su centro de estudios, logrando que éstos se familiaricen con el funcionamiento de las redes, el diseño de rutas y el trabajo con encaminadores o enrutadores de tipo Cisco. (Figura 4). También existen animaciones de procedimientos propios de las redes y de los protocolos.

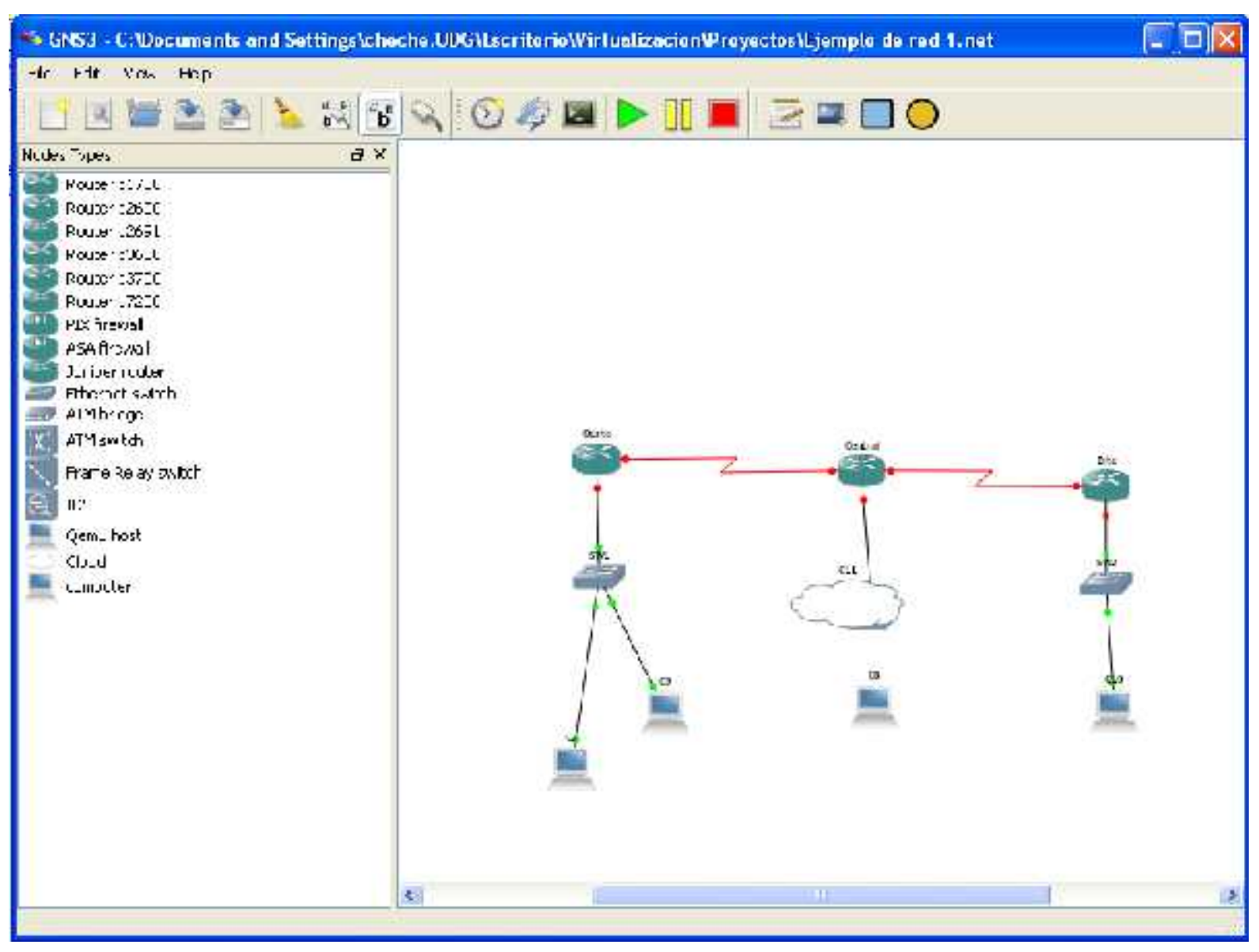

Figura 4. Simulador de redes y routers Cisco GNS3, en la figura se muestra una simulanción de una red formada por tres routers.

1.2.3 Elección de la herramienta adecuada para la confección del mapa.

También se hizo necesario decidir el software que se utilizaría para la confección y uso de los mapas creados, para ello, se realizaron extensas búsquedas en la redes públicas y privadas, y se detectó que existe una considerable cantidad de sistemas diseñados para el trabajo con mapas conceptuales, algunos, con propósitos comerciales, otros libres y de código abierto, y fue en éstos en los que se centró el análisis. La elección del software a emplear se basó en un conjunto de requisitos: 
Rev. SINAPSIS, Vol. 7, No 2, Diciembre 2015

- Debería tratarse de un paquete basado en software libre, con código fuera abierto, con arquitectura cliente - servidor, de manera que condicionara la posibilidad de compartir el trabajo creado y posibilitara el trabajo colaborativo.

- El sistema a utilizar tendría que contar con un serio respaldo bibliográfico, científicamente fundamentado.

- Se estableció cierta preferencia si se tratase de un software diseñado con un objetivo educativo principalmente con un elevado por ciento de utilización a escala mundial.

- Debería ser factible su empleo en la Universida de Granma.

El CMap, resultó ser el software elegido, el mismo cumplió con todos los requisitos que se establecieron para su elección, incluso, se pude comprobar que este software se ha convertido en un standard, pues muchas herramientas semejantes, miden, entre sus prestaciones, la compatibilidad con CMap.

El CMap posee dos módulos básicos, el CmapTools, que es la herramienta que se utiliza para crear, ver, editar o almacenar de forma local o en un servidor remoto los mapas conceptuales y el CMapServer, que es utilizado para almacenar mapas conceptuales, compartirlos, y facilitar el trabajo colaborativo.

El CMapServer se instaló en un servidor dedicado con sistema operativo Linux Fedora 10, este servidor cuenta con una dirección IP pública y le fueron implementadas las rutas de manera tal que se pudiera acceder al mismo desde cualquier punto de la red nacional RedUniv o desde la Internet.

Los clientes, CmapTools, con ayuda de los cuales se crearon los mapas, fueron instalados en varias estaciones de trabajo con Windows 2000 o XP.

\section{Resultados}

Actualmente, como resultado de esta investigación, existe un servidor de mapas conceptuales en la Universidad de Granma, que forma parte de la red mundial CMap, donde otras ciencias, como Estructuras de Datos, Sistemas Operativos, y Botánica, han publicado actualmente materiales de consulta para los estudiantes. 


\section{Rev. SINAPSIS, Vol. 7, Nº 2, Diciembre 2015}

Aunque en estos momentos solo contiene los mapas conceptuales antes mencionados, si se le da la explotación adecuada, podría actuar en un futuro como un repositorio compartido de modelos de conocimientos, el cual podría contener mapas de varias asignaturas y disciplinas, formando las llamadas "sopas de conocimientos", un índice para búsquedas de otros recursos y mapas conceptuales; facilitaría además la colaboración por hilos de discusión y la colaboración sincrónica durante la edición o construcción de mapas conceptuales. En la figura 5, se destaca el servidor de mapas conceptuales de la Universidad de Granma, insertado en la red mundial CMap.

Este servidor, suministra, a través de un pequeño servidor Web, versiones en HTML de los mapas conceptuales que contiene, lo que facilita que si no se dispone del CMapTools, es decir, de la herramienta cliente, sea posible acceder a los mapas existentes solamente auxiliándose de un navegador como Internet Explorer, Netscape u otro. No obstante ser lo anterior una vía de acceso a recursos y mapas en un servidor CMap, la manera óptima de explorar o consultar un mapa conceptual en CMap es mediante la herramienta cliente, creada para este fin (CMapTools), pues algunos recursos se omiten en la versión Web. La URL del servidor Web actualmente es: http://cmap.udg.co.cu.

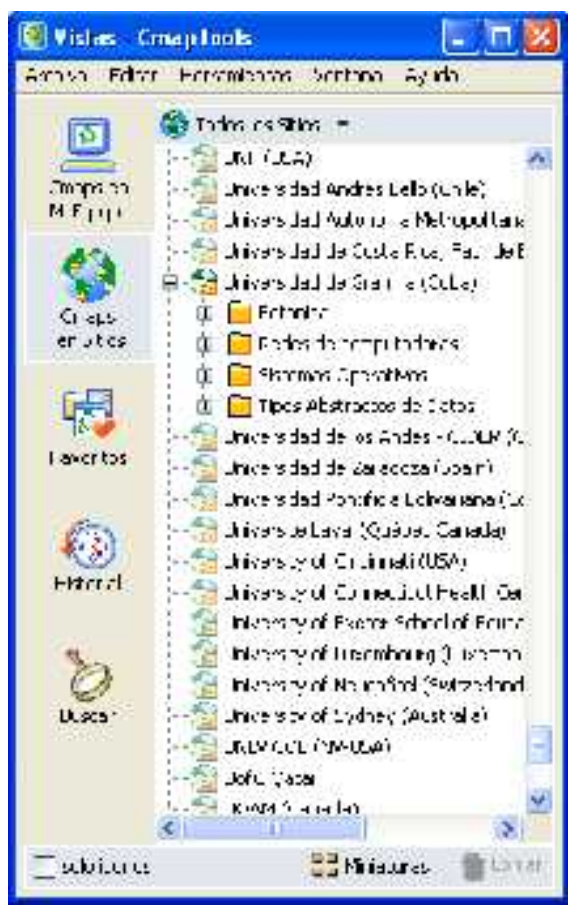

Fig. 5: Comunidad Mundial Cmap, destacando el servidor Cmap de la Universidad de Granma. 


\section{Rev. SINAPSIS, Vol. 7, Nº 2, Diciembre 2015}

En estos momentos, los estudiantes de carreras de perfil informático, cuentan, en el servidor CMap de la Universidad de Granma con un Mapa Conceptual dedicado a la asignatura Redes de Computadoras, el cual constituye una efectiva herramienta para mejorar la calidad del proceso docente en un entorno a distancia o semi presencial, facilita la construcción del conocimiento, la definición de los conceptos fundamentales y la relación entre los mismos, ofreciendo un método idóneo para la autopreparación de los estudiantes y una mejor comprensión de los contenidos.

El mapa tiene asociados una notable cantidad de recursos adicionales: imágenes, animacioneses, páginas web, documentos, documentos en PDF, etc, además, por la no existencia en la mayoría de los centros de educación superior cubanos, de equipos sofisticados de red, y por las características de la asignatura, se priorizó la búsqueda y obtención de materiales que compensaran estas dificultades, como videos y simulaciones. Pone a disposición del Proceso Docente y sobre todo los estudiantes, aplicaciones de simulación para la realización de prácticas de laboratorios virtuales, lo que mejora el nivel de aprendizaje de los alumnos en la asignatura, pues con ello se facilita que éstos adquieran habilidades que en cursos en los que no se empleaban estas herramientas, no se lograban.

Es importante señalar el papel que debe jugar esta y otras herramientas similares en la generalización del plan de estudios D y la Universalización de la Educación Superior, que incluye la creación de las sedes universitarias municipales, donde las actividades no presenciales deben llevar el protagonismo. Cuba ha hecho grandes inversiones para poder lograr este objetivo y potenciar la educación semipresencial o a distancia en las sedes universitarias, por ejemplo, actualmente, todas las sedes se encuentran conectadas a la Red Universitaria Nacional (RedUniv), el desarrollo de todo este andamiaje a nivel nacional, potenciará considerablemente el uso de plataformas, herramientas y aplicaciones que faciliten estas nuevas modalidades de la educación, tales como el CMapTools.

El servidor CMap de la Universidad de Granma, facilitará las interacciones entre estudiantes y profesores, y no solo en la Universidad sino también, en las sedes universitarias municipales, condición muy favorable para mejorar la calidad de la docencia.

En la Universidad de Granma, los profesores de la asignatura "Redes de Computadoras" que dirigen el proceso docente, tanto en la Cede Central, como en las otras, han implantado a 


\section{Rev. SINAPSIS, Vol. 7, Nº 2, Diciembre 2015}

modo experimental, el uso y empleo del mapa conceptual que se está creando, y con ello, el uso de la aplicación CMAP por parte de los profesores que imparten la docencia y estudiantes que cursan la carrera esta nueva modalidad de estudio.

Tampoco se puede excluir de este informe, el impacto que esta herramienta ejercerá en el resto de las signaturas de la carrera y el año, principalmente a través de la vinculación horizontal y vertical de esta herramienta con otras asignaturas de ésta.

\section{Conclusiones}

- Se presenta una propuesta organizativa para la asignatura Redes de Computadoras que facilita el acceso a sus contenidos y brinda recursos virtuales de apoyo al aprendizaje en entornos educativos semipresenciales.

- Se propone el empleo de un simulador de dispositivos y redes, para la realización de prácticas de laboratorios virtuales relacionadas con los encaminamientos, y la configuración de enrutadores Cisco, para las dos versiones del protocolo IP empleadas actualmente.

- Se aporta un servidor de mapas conceptuales en la Universidad de Granma, en el que cualquier profesor, investigador, puede representar el contenido de las materias que imparte. A éste, se puede acceder desde cualquier computadora conectada a la red Universitaria Nacional o a Internet, lo que propicia el trabajo colaborativo durante la construcción de mapas conceptuales y la posibilidad de compartir el conocimiento creado.

- La propuesta organiza los contenidos a través de mapas conceptuales que establecen asociaciones entre sus diferentes conceptos, a los que se asocian recursos de media de todo tipo: páginas web, imágenes y esquemas de estructuras de redes, informaciones, simulaciones y animaciones que auxilien el proceso de enseñanza.

\section{Referencias}

1. Ausubel, D., J. Novak, et al. (1978). Educatinal psychology: a cognitive view. New York: Holt, Rinehart and Winston. , México Trillas.

2. Ausubel, D., J. D. Novak, et al. (1989). Psicología Educativa, Mexico, Trillas.

3. Benegas, M. L. and R. Chrobak (2004). HERRAMIENTAS

COMPUTACIONALES Y EL APRENDIZAJE SIGNIFICATIVO. First Int. Conference on Concept Mapping. Pamplona. 
Rev. SINAPSIS, Vol. 7, N², Diciembre 2015

4. Brunner, J. (2002). Desarrollo Cognitivo y Educación, Madrid, Morata.

5. Cornella, A. (1999). "En la sociedad del conocimiento, la riqueza está en las ideas.", 2004, from http://www.infonomics.net/cornella/afundesco.pdf.

6. Iriarte, L., M. Duch, et al. (2002). Mapas Conceptuales y Objetos de Aprendizaje. I Simposio Pluridisciplinar sobre Diseño, Evaluación y Descripción de Contenidos Educativos Reutilizables, Guadalajara, Universidad de Murcia.

7. Sánchez, I. R. A. (2003). "La educación a distancia. ACIMED. ." ACIMED 11(1): 3-4. 
Rev. SINAPSIS, Vol. 7, Nº 2, Diciembre 2015 